\title{
Comparative Study on Dynamic Analysis of Elevated Water Tank Frame Staging and Concrete Shaft Supported
}

\author{
Mor Vyankatesh K. ${ }^{1}$, More Varsha T. ${ }^{2}$ \\ ${ }^{I}$ (PG Student, Department of civil Engineering, J.N.E.C, Aurangabad, Maharashtra, India) \\ ${ }^{2}$ (Assistant Professor, Department of civil Engineering, J.N.E.C, Aurangabad, Maharashtra, India)
}

\begin{abstract}
This paper presents comparative study of elevated water tanks subjected to dynamic loading supported on RC framed structure and concrete shaft structure with different capacities and placed in different seismic zones. History of earthquake reveals that it have caused numerous losses to the life of people in its active time, and also post earthquake time have let people suffer due to damages caused to the public utility services. Either in urban or rural areas elevated water tanks forms integral part of water supply scheme, so its functionality pre and post earthquake remains equally important. These events showed that importance of supporting system is uncompromising for elevated tank as compared to any other type of tank. Damages caused are the results of unsuitable design of supporting system; wrong selection of supporting system, etc. These structures have heavy mass concentrated at the top of slender supporting system hence these structures are especially vulnerable to horizontal forces due to earthquakes. This paper presents the dynamic analysis of elevated water tanks with respect to the latest IS code published for liquid retaining structures by Bureau of Indian Standards i.e. IS 1893 (Part 2) : 2014. Comparison of elevated tanks with different supporting system, capacities and seismic zones states that these parameters may considerably change the seismic behaviour of tanks.
\end{abstract}

Keywords: RC framed supported, concrete shaft supported, Convective hydrodynamic pressure, Impulsive hydrodynamic pressure, STAAD Pro V8i.

\subsection{General}

\section{Introduction}

Indian sub-continent is highly vulnerable to natural disasters like earthquake, draughts, floods, cyclones etc. According to IS code 1893(Part 1):2000, more than 60\% of India is prone to earthquakes. The earthquake of 26 January 2010 in Gujarat was unprecedented for the entire country, then public learnt first time that the scale of disaster could have been far lower had the construction in the region compiled with codes of practice for earthquake prone regions. These natural calamities are causing many casualties and innumerable property loss every year. After an earthquake the loss which cannot be recovered are the life loss. Collapse of structures causes people to life loss. Hence badly constructed structures kill people more than earthquake itself. Hence it becomes important to analyse the structures properly.

Seismic safety of liquid storage tanks is of considerable importance, as tanks storing highly concentrated liquids in industries, or in transporting vehicles, can cause considerable harm for human society if damaged. Water supply being the lifeline facility must remain functional following disaster to carter the need of drinking and fire fighting. Since elevated water tanks are integral part of water supply scheme, its study and improvising it becomes need of time. Elevated water tanks can be classified depending upon its shape and supporting.

Based on shape, elevated tanks can be classified as;

1. Circular Tank.

2. Rectangle Tank.

3. Square Tank.

4. Conical Tank.

5. Intze Tank.

Based on supporting system, elevated tanks can be classified as;

1. Shaft supported elevated tanks.

2. Framed staging / Trestle supported elevated tanks.

Damages to the elevated tanks with both type of supporting system stated above are noted during earthquake. Hence it becomes necessary to evaluate the optimum selection of supporting system for the predefined requirements of tank. This paper presents comparison of elevated tanks with different supporting system, capacities, and seismic zones. All the seismic analysis parameters are evaluated using the recommended 
procedure in latest code as well as in IIT-GSDMA guidelines, and is concentrated mainly to the Sloshing effect that is happening in the water during earthquake.

\subsection{Literature Review:}

A Much of literature has been presented in the form of technical papers till date on dynamic analysis of elevated water tanks RC framed supported and concrete shaft supported. Different points are covered in that relevance i.e. dynamic analysis, sloshing effect on tank, dynamic response of framed staging etc. Some of them are listed below.

George W. Housner [1]: Chilean earthquake that took place in 1960 was the main plot behind this paper. He stated about the relation between motion of water w.r.t tank and whole structure w.r.t ground. Fully filled tank, empty tank, partially filled tank, were the three cases considered by him. Sloshing effect was neglected in first two cases as there is no free board in first case and other no water to cause sloshing motion. Here the whole structure behaves as one-mass structure. But in the third case sloshing effect must be considered, because here the structure behaves as two-mass structure. Concluding he stated that the maximum force to which a half-filled tank can be subjected is less than that of totally filled tank.

Dr. Suchita Hirde \& Manoj Hedaoo [2]: Hydrodynamic analysis of elevated water tanks for various heights, capacity and soil conditions. The effect of height of water tank, earthquake zones and soil conditions on earthquake forces have been presented in this paper. They considered RCC circular tank with M-20 grade of concrete and Fe-415 grade of steel for analysis. Capacity of 50,000 lit and 100.000 with staging height of $12 \mathrm{~m}$, $16 \mathrm{~m}, 20 \mathrm{~m}, 28 \mathrm{~m}$ with $4 \mathrm{~m}$ height of panel are considered for analysis. Following were the conclusions made in the paper [1] Seismic forces are directly proportional to the seismic zones. [2] Seismic forces are inversely proportional to the height of the supporting system. [3] Seismic forces increase with increase in capacity of tank. [4] Seismic forces are higher in soft soil than that of medium and higher in medium soil than that of hard.

R Livaoglu \& Dogangun [3]: This paper presents the response of the supporting system of water towers. Here they have considered frame staging as well as concrete shaft as supporting system for elevated water tanks. In this paper they concluded that where there is high risk of seismic force, the cylindrical shaft support system may be used because of having important advantages than the common used frame type system. They also found that roof displacement response for frame support is higher than that of concrete shaft support system.

Prasad S. Barve, Ruchi P. Barve [4]: This paper states the seismic behaviour of intze tank supported on concrete shaft. Here the study is done in accordance with the change in aspect ratio i.e. $\mathrm{h} / \mathrm{d}$ ratio where, $\mathrm{h}$ is height of water in tank and $\mathrm{d}$ is internal diameter of tank. It concludes that with increase in $\mathrm{h} / \mathrm{d}$ ratio, the impulsive fluid pressure increases with increase in base shear and base moment for that tank. As h/d ratio increases there is decrease in convective fluid pressure of the tank, since convective mass of water comprises of sloshing effect observed during earthquake hence it's necessary to pick optimum $\mathrm{h} / \mathrm{d}$ ratio while designing tank components.

\subsection{Objective}

[1] The main objective of this paper is to study the hydrodynamic effect on elevated water tank, with different supporting system i.e. framed staging and concrete shaft placed in different seismic zones.

[2] Also to compare the analysis results of base shear and base moment with different capacities. Comparing impulsive and convective pressure results as they may exert pressure in different magnitude.

\subsection{Impulsive and Convective Mass}

\section{System Development}

During an earthquake, elevated water tank with free liquid surface is subjected to horizontal ground motion, and liquid in tank as well as tank wall are subjected to horizontal acceleration. Here the liquid in the lower region of the tank behaves like a mass that is rigidly connected to tank wall. This mass is stated as impulsive liquid mass $\left(\mathrm{m}_{\mathrm{i}}\right)$, which accelerates along with the wall and induces impulsive hydrodynamic pressure on tank wall as well as base. Liquid mass in the upper region o4n the tank undergoes sloshing motion. This mass is stated as convective liquid mass $\left(\mathrm{m}_{\mathrm{c}}\right)$ and it exerts convective hydrodynamic pressure on tank wall and base. Thus the total liquid mass gets divided into two parts i.e. impulsive mass and convective mass. These mass are suitably represented in spring mass model.

A qualitative description of impulsive and convective hydrodynamic pressure distribution on tank wall is given in Figure 1 


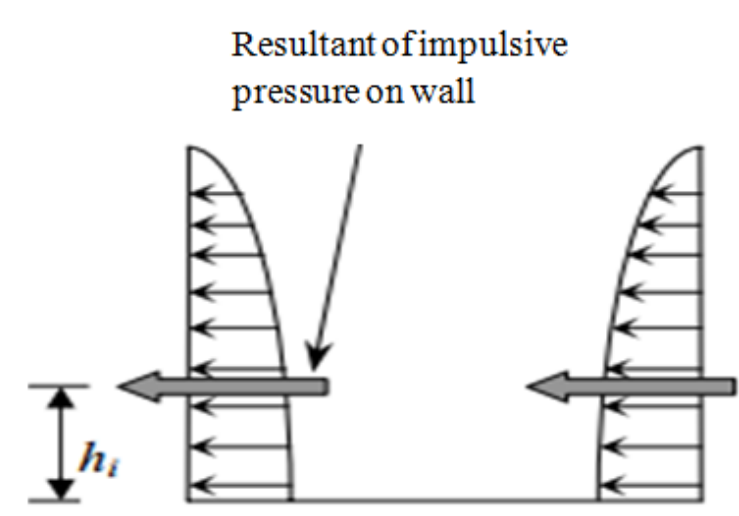

Fig.1 (a) Impulsive pressure on wall

Resultant of convective pressure on wall



Fig.1 (c) Convective pressure on wall
Resultant of impulsive pressure on wall and base

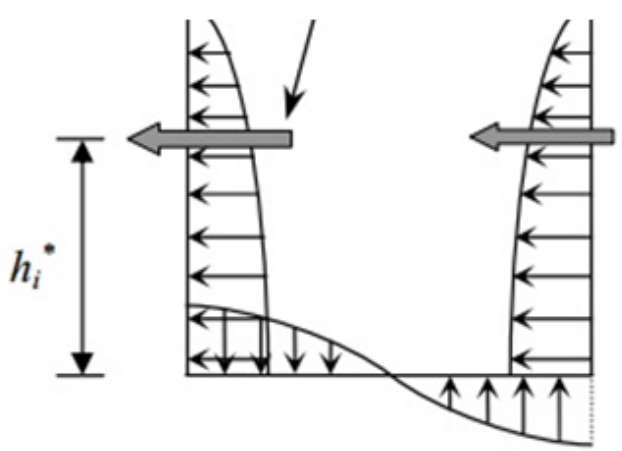

Fig.1 (b) Impulsive pressure on wall and base

Resultant of convective pressure on wall and base

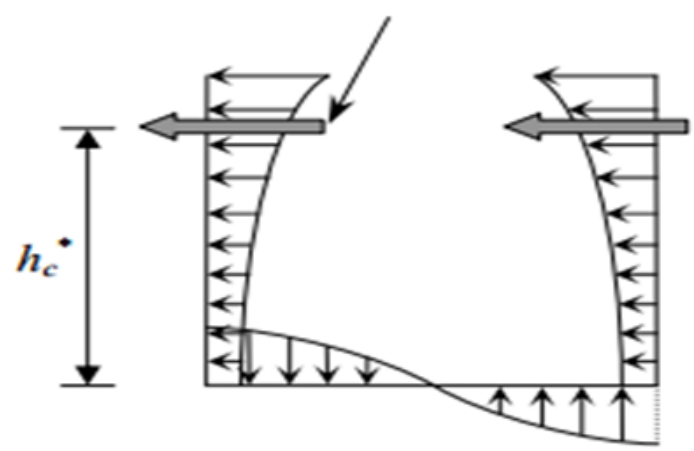

Fig.1 (d) Convective pressure on wall and base

\subsection{Spring Mass Model for Seismic Analysis of Elevated Tank}

Most of the elevated tanks are partially filled. Hence two-mass idealization of the tank is more appropriate than one-mass model. It is also being commonly used in international codes. The response of twodegree of freedom system can be obtained by elementary structural dynamics. However, two periods are well separated for most of the tanks. Hence, system can be considered as two uncoupled single degree of freedom system. This two uncoupled single degree of freedom systems, one representing impulsive plus structural mass behaving as an inverted pendulum with lateral stiffness equal to the stiffness of staging, $\left(\mathrm{k}_{\mathrm{s}}\right)$ and the other convective mass with spring of stiffness, $\left(\mathrm{k}_{\mathrm{c}}\right)$.



Fig.2 (a) Elevated tank

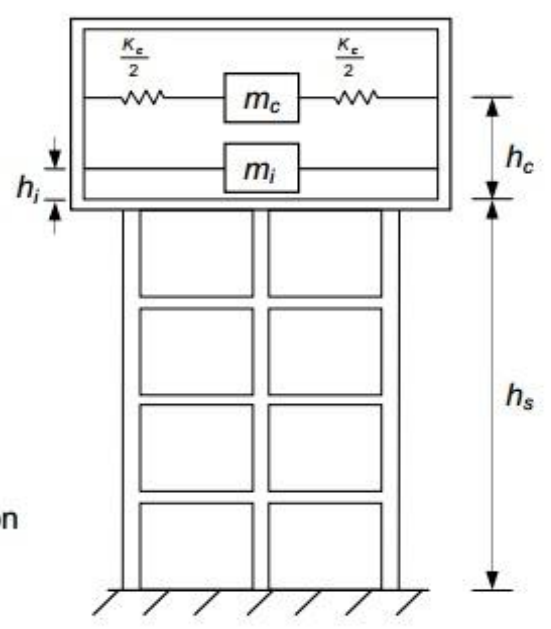

Fig.2 (b) Spring mass model 


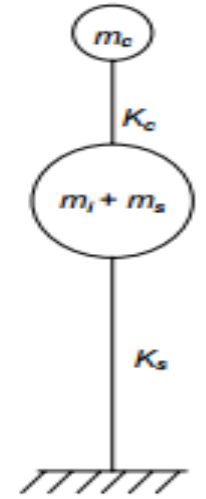

Fig.2 (c) Two-mass idealization of elevated tank
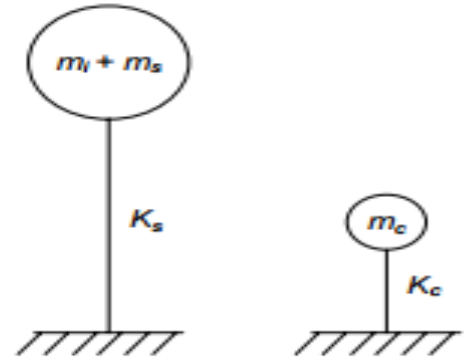

Fig.2 (d) Equivalent uncoupled system

\subsection{Lateral Stiffness}

Lateral stiffness of staging is defined as the force required to be applied at the CG of tank so as to get a corresponding unit deflection. From the deflection of CG of tank due to an arbitrary lateral force one can get stiffness of frame staging. STAAD pro software is used to model the staging.

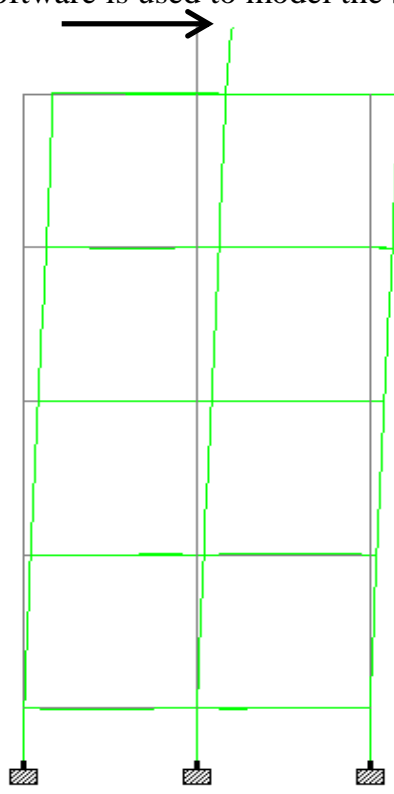

Fig.3 Deflected shape of tank staging for an arbitary force

Lateral stifness of concrete shaft is calculated according to the guidelines by IITK-GSDMA. Here, shaft is considered as cantilever about the height of shaft from top of footing upto bottom of circular ring beam. Lateral stiffness is given by: $\mathrm{K}_{\mathrm{s}}=3 \mathrm{EI} / \mathrm{L}^{3}$...(1). Where, $\mathrm{E}=$ Modulus of elasticity, $\mathrm{I}=$ Moment of inertia of shaft cross section, $\mathrm{L}=$ Height of shaft.

Minimum thickness of concrete shaft:

As per IS 1893 (Part 2): 2014, clause 8.2.1 minimum thickness of shaft is recommended as $150 \mathrm{~mm}$ for shaft diameter upto $4 \mathrm{~m}$. Shaft with diameter leass than $8 \mathrm{~m}$ are calculated by: $\mathrm{t}_{\min }=150+(\mathrm{D}-4000) / 80$..(2) , and for shafts with diameter equal to or greater than $8 \mathrm{~m}$ are claculated by : $t_{\min }=200+(D-8000) / 120$..(3) where, $D$ $=$ diameter of shaft in $\mathrm{mm}$.

\subsection{Numerical Statement}

Dynamic analysis of circular elevated water tanks, supported on RC frame staging and concrete shaft structure of different capacities and following specifications are performed as per IS 1893 (Part 2): 2014 for medium soil condition and zone II, III, IV, V. As capacity increases, number of columns supporting in frame staging structure of tank are increased with sizes of components kept constant for all tanks. Where as for tanks supported on concrete shaft, the sizes of components are changed as shown below with increase in capacity of tank. A $1.2 \mathrm{~m}$ wide gallery is considered around the periphery of all tanks for access. Grade of concrete, grade of steel and soil condition for circular elevated tanks are M-20, Fe415 and medium soil respectively. All tanks are provided with appropriate free board.Here, $\mathrm{H}=$ Lowest supply level from ground, $\mathrm{D}=$ Internal diameter of tank, 
Comparative Study On Dynamic Analysis Of Elevated Water Tank Frame Staging And Concrete...

$d_{s}=$ Diameter of shaft, $h=$ Height of water in tank from bottom of wall, $N=$ Number of columns, $t=$ Thickness of shaft, where as, the ratio of $\mathrm{H} / \mathrm{D}$ and $\mathrm{h} / \mathrm{D}$ is kept constant for all capacities of tank.

Table 1: Geometrical Specifications for frame supported tanks.

\begin{tabular}{|c|c|c|c|c|c|c|c|}
\hline Tank & Capacity & $\mathbf{H}$ & D & h & H/D & h/d & $\mathbf{N}$ \\
\hline & $\left(\mathrm{m}^{3}\right)$ & (m) & (m) & (m) & - & - & (no's) \\
\hline T1 & 150 & 12 & 8 & 3 & \multirow{4}{*}{$\begin{array}{c}1.5 \\
( \pm 0.1)\end{array}$} & \multirow{4}{*}{$\begin{array}{c}0.36 \\
( \pm 0.1)\end{array}$} & 5 \\
\hline $\mathrm{T} 2$ & 250 & 14 & 9.5 & 3.5 & & & 9 \\
\hline T3 & 500 & 18 & 12 & 4.5 & & & 13 \\
\hline T4 & 750 & 21 & 14 & 5 & & & 17 \\
\hline
\end{tabular}

Table 2: Geometrical Specifications for shaft supported tanks.

\begin{tabular}{|c|c|c|c|c|c|c|c|c|}
\hline Tank & Capacity & $\mathbf{H}$ & $\mathbf{D}$ & $\mathbf{d}_{\mathbf{s}}$ & $\mathbf{h}$ & $\mathbf{H} / \mathbf{D}$ & $\mathbf{h} / \mathbf{d}$ & $\mathbf{t}$ \\
\hline & $\left(\mathrm{m}^{3}\right)$ & $(\mathrm{m})$ & $(\mathrm{m})$ & $(\mathrm{m})$ & $(\mathrm{m})$ & - & - & $(\mathrm{mm})$ \\
\hline S1 & 150 & 12 & 7.8 & 5.5 & 3 & & & 150 \\
\hline S2 & 250 & 14.4 & 8.6 & 6.13 & 4 & 1.5 & 0.36 & 180 \\
\hline S3 & 500 & 18 & 11.2 & 8 & 4.5 & $( \pm 0.1)$ & $( \pm 0.1)$ & 200 \\
\cline { 1 - 5 } \cline { 5 - 6 } & & 21 & 13 & 8.9 & 4.9 & & & 220 \\
\hline
\end{tabular}

Please note the ratio $\mathrm{h} / \mathrm{d}$ for tanks supported on concrete shaft are calculated from equivalent circular tank of same volume and diameter equal to diameter of tank at top level.

Table 3: Constants.

\begin{tabular}{|c|l|l|}
\hline Sr No. & Constant & Values \\
\hline \multirow{3}{*}{1} & Seismic intensity (Zone II) & 0.1 (as per IS code 1893 Part 2) \\
\cline { 2 - 3 } & Zone III & 0.16 \\
\cline { 2 - 3 } & Zone IV & 0.24 \\
\cline { 2 - 3 } & Zone V & 0.36 \\
\hline \multirow{2}{*}{2} & Response reduction factor (R), for tanks supported on frame staging & 4 (as per IS code 1893 Part 2) \\
\cline { 2 - 3 } & Response reduction factor (R), for tanks supported on concrete shaft & 3.5 (as per IS code 1893 Part 2) \\
\hline 3 & Importance factor (I) & 1.5 \\
\hline
\end{tabular}

Table 4: Components Sizes for frame supported tanks.

\begin{tabular}{|c|l|l|}
\hline Sr No. & Component & Sizes $(\mathbf{m m})$ \\
\hline 1 & Roof slab & 150 \\
\hline 2 & Cylindrical wall & 200 \\
\hline 3 & Base slab & 200 \\
\hline 4 & Roof beams & $230 \times 450$ \\
\hline 5 & Floor beams & $300 \times 600$ \\
\hline 6 & Braces & $300 \times 450$ \\
\hline 7 & Gallery & 110 \\
\hline 8 & Columns & 500 \\
\hline
\end{tabular}

Table 5: Components Sizes for shaft supported tanks

(Sizes changes as per increase in tank capacity)

\begin{tabular}{|c|l|l|}
\hline Sr No. & Component & Sizes (mm) \\
\hline 1 & Top Dome & 110 to 150 \\
\hline 2 & Cylindrical wall & 180 to 220 \\
\hline 3 & Top ring beam & $250 \times 300$ to $300 \times 450$ \\
\hline 4 & Bottom ring beam & $300 \times 500$ to $300 \times 600$ \\
\hline 5 & Circular ring beam & $500 \times 600$ to $500 \times 750$ \\
\hline 6 & Bottom Dome & 200 to 220 \\
\hline 7 & Conical Dome & 230 to 250 \\
\hline
\end{tabular}

III. Results And Discussion

For all the above stated Circular elevated tanks, RC frame staging system was modelled in STAAD Pro and arbitrary load was applied at the centre of gravity of the tank. Following are the values of stiffness calculated (T1 toT2). Also stiffness for tanks supported on concrete shaft is calculated below (S1 to S2).

Table 6: Stiffness.

\begin{tabular}{|l|c|l|c|}
\hline Tank & Stiffness $(\mathbf{K n} / \mathbf{m})$ & Tank & Stiffness $(\mathbf{K n} / \mathbf{m})$ \\
\hline T1 & 10570.82 & S1 & 259911 \\
\hline T2 & 12156.58 & S2 & 270301 \\
\hline T3 & 17241.38 & S3 & 363334 \\
\hline T4 & 18867.92 & S4 & 413102 \\
\hline
\end{tabular}




\subsection{Time Period}

Time period in impulsive mode $\left(\mathrm{T}_{\mathrm{i}}\right)$ and time period in convective mode of vibration $\left(\mathrm{T}_{\mathrm{c}}\right)$ is calculated and compared with capacities of tank. Since time period is same for all seismic zones, only single curve represents time period in all zones below.



Fig.4 Capacity v/s Time period (impulsive mode)

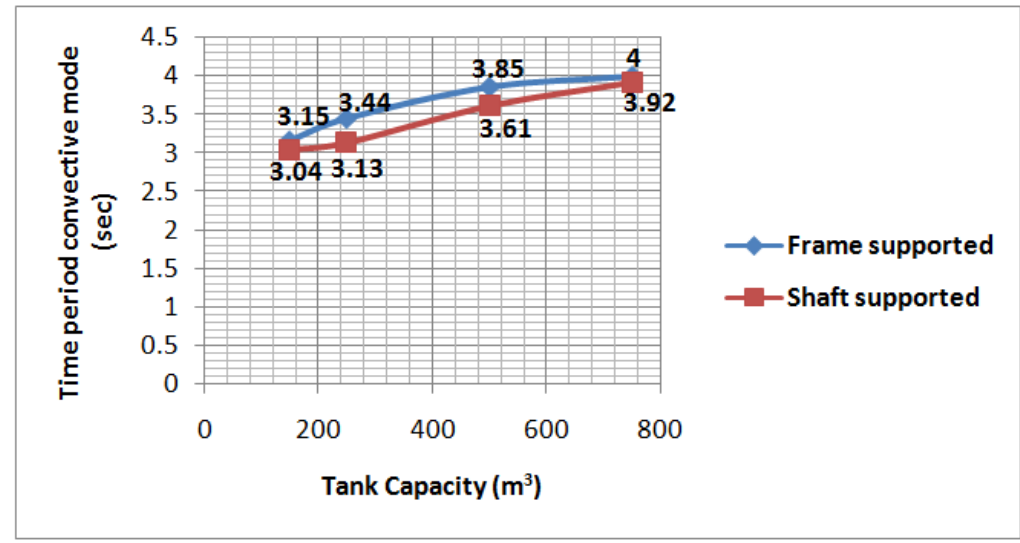

Fig.5 Capacity v/s Time period (convective mode)

\subsection{Base Shear}

Total base shear $(\mathrm{V})$, the horizontal force which acts at the bottom at the staging is resultant of two different case base shears, one for impulsive mode $\left(\mathrm{V}_{\mathrm{i}}\right)$ and for convective mode $\left(\mathrm{V}_{\mathrm{c}}\right)$. It represents the increase in base shear with increase in capacity of tank.

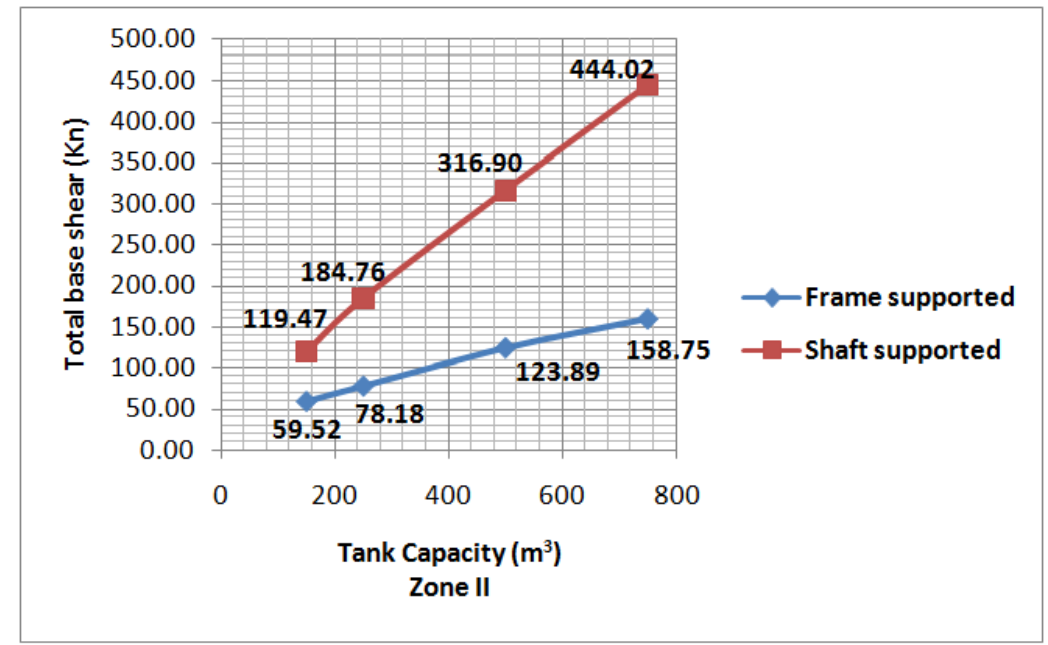

Fig.6 Capacity v/s Total base shear (Zone II) 


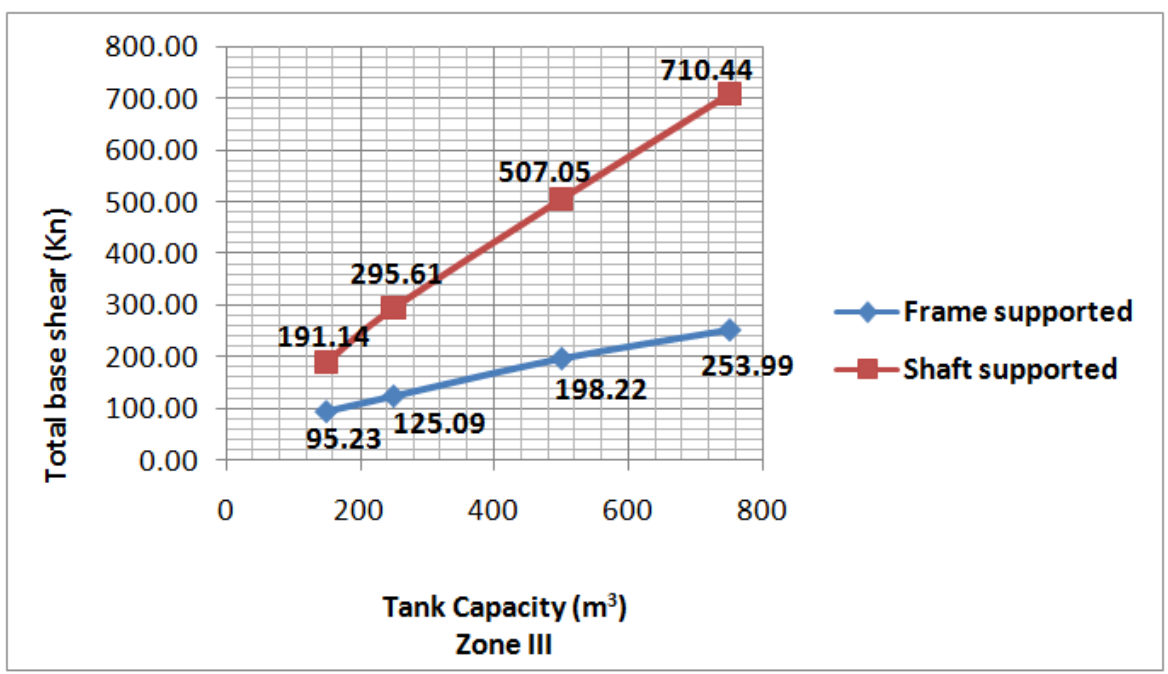

Fig.7 Capacity v/s Total base shear (Zone III)

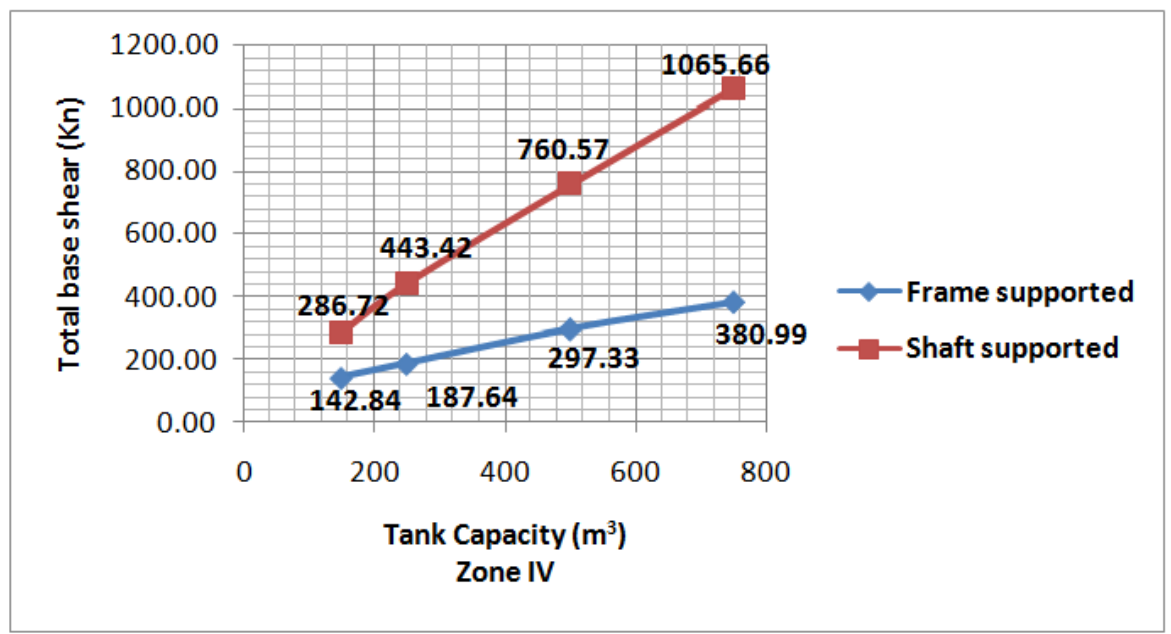

Fig.8 Capacity v/s Total base shear (Zone IV)

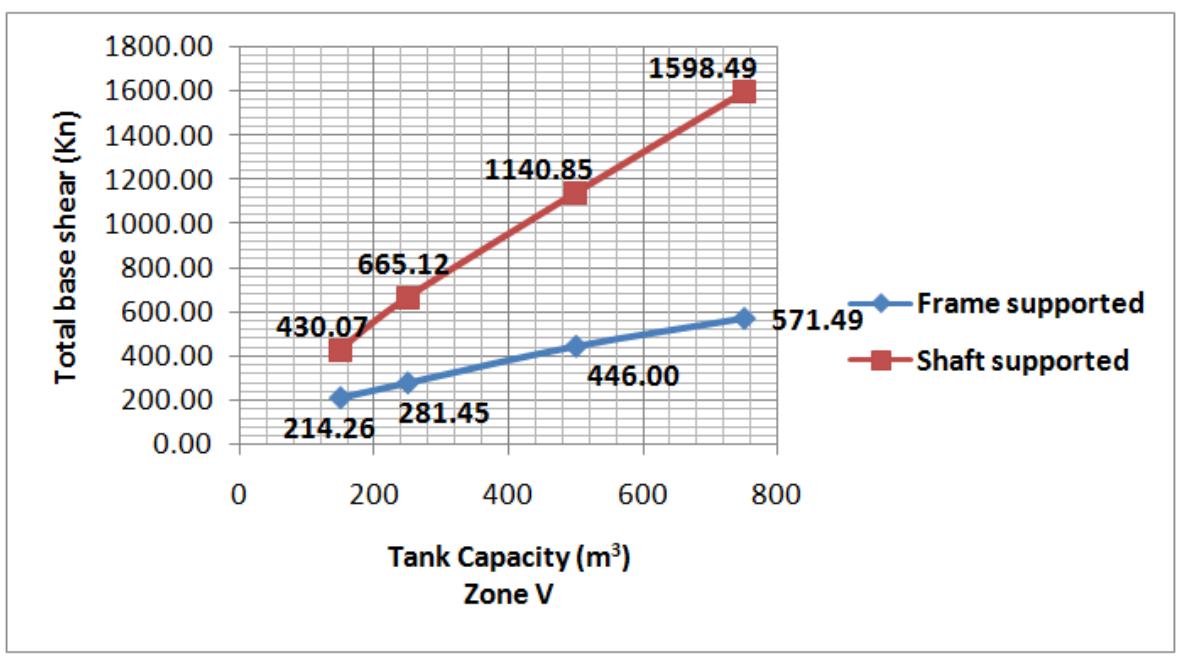

Fig.9 Capacity v/s Total base shear (Zone V)

\subsection{Base Moment}

Since the large mass accumulation at the top of slender supporting system, the overturning moment is the important parameter at the time of designing elevated water tank. Its observed that base moment for tanks supported on frame staging is less than that of tanks supported on concrete shaft. 


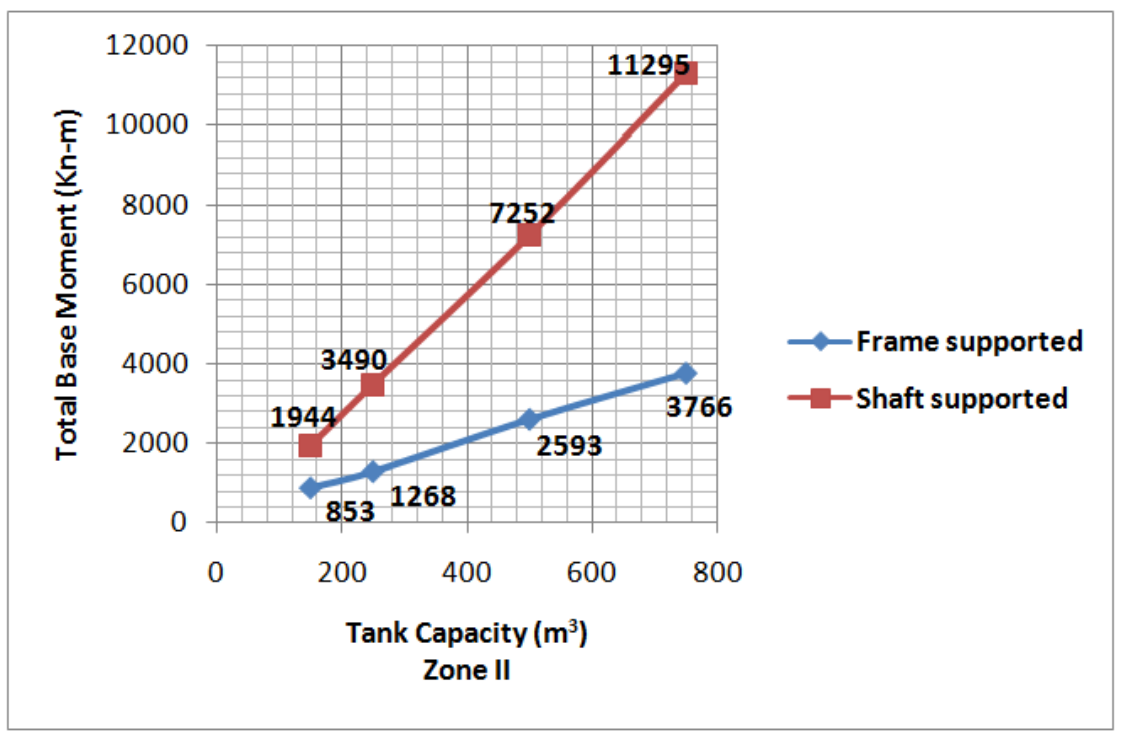

Fig.10 Capacity v/s Total Base Moment (Zone II)



Fig.11 Capacity v/s Total Base Moment (Zone III)

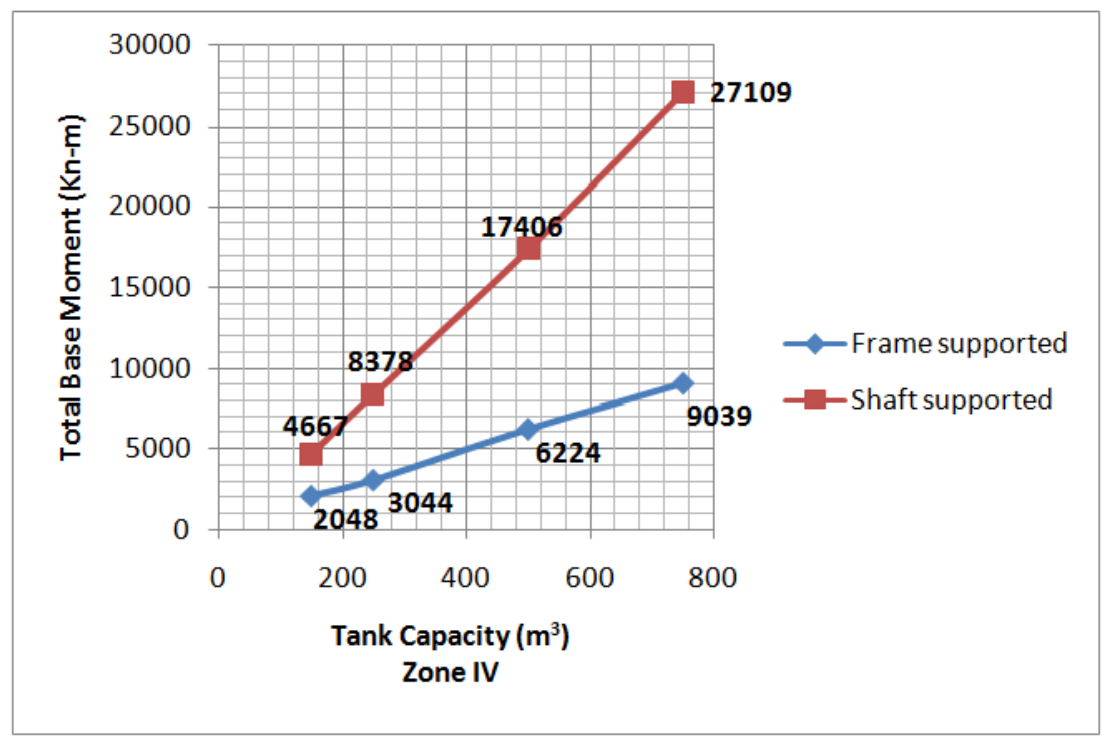

Fig.12 Capacity v/s Total Base Moment (Zone IV) 




Fig.13 Capacity v/s Total Base Moment (Zone V)

\subsection{Sloshing Wave Height}

Free Board to be provided in tank based on the maximum value of sloshing wave height. This is particularly for the important tanks containing toxic liquids, where loss of liquid needs to be prevented. Or if required free board is not provided, roof structure of tank should be deigned for resisting uplift pressure due to sloshing liquid.

Table 7: Sloshing Wave Height.

\begin{tabular}{|l|l|l|l|l|}
\hline \multirow{2}{*}{ Tank } & \multicolumn{4}{|c|}{ Sloshing wave height (mm) } \\
\cline { 2 - 5 } & Zone II & Zone III & Zone IV & Zone V \\
\hline T1 & 129 & 207 & 310 & 466 \\
\hline T2 & 140 & 225 & 337 & 506 \\
\hline T3 & 158 & 253 & 380 & 570 \\
\hline T4 & 178 & 285 & 428 & 642 \\
\hline S1 & 130 & 208 & 313 & 470 \\
\hline S2 & 139 & 223 & 335 & 503 \\
\hline S3 & 157 & 252 & 379 & 568 \\
\hline S4 & 169 & 270 & 405 & 608 \\
\hline
\end{tabular}

\section{Conclusion}

Following conclusions are made based on the aforementioned analysis presented in this paper.

1) Base shear for elevated tanks, supported on concrete shaft is greater than that of elevated tanks supported on frame staging.

2) Base moment being important parameter while designing the structure is considerably greater for tanks with concrete shaft supported. Hence the areas with high seismic intensity, threat to tank with shaft supporting are more than that of staging support.

3) Time period in impulsive mode for shaft supported tanks and frame supported tanks differ subsequently. But for convective mode the difference is less comparatively.

4) The deflection of staging is found to be decreasing with increase of capacity and change in staging pattern, further causing increase in its stiffness.

5) Sloshing wave height is approximately same for the tanks with different supporting system, but it differs for tanks as the capacity increases.

\section{References}

[1]. George W. Housner, 1963 "The Dynamic Behaviour of Water Tank" Bulletin of the Seismological Society of America. Vol.53, No.2, pp. 381-387. February 1963.

[2]. Dr Suchita Hirde, Dr Manoj Hedaoo, "Seismic Performance of Elevated Water Tank", International Journal of Advanced Engineering Research and Studies/Vol.I/2011.

[3]. Prasad S Barve, Ruchi P Barve 2015 "Parametric Study to understand the Seismic Behaviour of Inze Tank Supported on Shaft" International journal of engineering sciences \& research technology Barve, 4(7): July, 2015

[4]. R. Livaoglu and A. Dogangun May 2007 "An Investigation About Effects of supporting systems on Fluid-elevated tanks Interaction" SS: Special Structures Paper ID: SS148, Tehran, Iraq.

[5]. Mangulkar Madhuri N, Gaikwad Madhukar V, "Review On Seismic Analysis of Elevated Water Tank". International Journal of Civil Engineering and Technology (IJCIET), Volume 4, Issue 2, March-April 2013

[6]. Soheil Soroushnia, Sh Tavousi Tafreshi, F. Omidinasab, "Seismic Performance of RC Elevated Water Tanks with Frame Staging and Exhibition Damage Pattern" Science Direct ELSEVIER Procedia Engineering 14 (2011) 3076-3087

[7]. Sudhir K Jain and M. S. Mdhekar, October-1993, "Proposed provisions for aseismic design of liquid storage tanks" Journals of Structural Engineering Vol-20, No-03.

[8]. Sudhir K Jain, O.R. Jaiswal, Spetember-2005, Journal of Structural Engineering, Vol-32, No03.

[9]. Bureau of Indian Standards "Criteria For Earthquake Resistant Design Of Structures" IS Code 1893 (Part2):2014, August 2014

[10]. IITK-GSDMA guidelines for seismic design of liquid storage tanks. 